\title{
Perceptions of Portuguese university teachers about critical thinking educational practices
}

\author{
Felicidade Morais \\ ECHS - Departamento de Letras, Artes e \\ Comunicação / CELGA-ILTEC \\ Universidade de Trás-os-Montes e Alto \\ Douro / Universidade de Coimbra \\ Vila Real / Coimbra, Portugal \\ mmorais@utad.pt \\ Daniela Pedrosa \\ ECT - Departamento de Engenharias \\ Univ. de Trás-os-Montes e Alto Douro \\ Vila Real, Portugal \\ dpedrosa@utad.pt \\ Maria M. Nascimento \\ ECT - Departamento de Matemática / \\ LabDCT/CITDFF \\ Universidade de Trás-os-Montes e Alto \\ Douro / Universidade de Aveiro \\ Vila Real / Aveiro, Portugal \\ mmsn@utad.pt
}

\author{
Helena Silva \\ ECHS - Departamento de Educação / CIIE \\ Universidade de Trás-os-Montes e Alto \\ Douro / Universidade do Porto \\ Vila Real / Porto, Portugal \\ helsilva@utad.pt \\ Rita Payan-Carreira \\ ECAV-Departamento de Zootecnia / \\ CECAV \\ Universidade de Trás-os-Montes e Alto \\ Douro \\ Vila Real, Portugal \\ ritapay@utad.pt
}

\author{
Gonçalo Cruz \\ ECT - Departamento de Engenharias \\ Universidade de Trás-os-Montes e Alto \\ Douro \\ Vila Real, Portugal \\ goncaloc@utad.pt \\ Caroline Dominguez \\ ECT - Departamento de Engenharias / \\ LabDCT/CITDFF \\ Universidade de Trás-os-Montes e Alto \\ Douro / Universidade de Aveiro \\ Vila Real / Aveiro, Portugal \\ carold@utad.pt
}

\begin{abstract}
Promoting students' Critical Thinking (CT) in Higher Education Institutions (HEI) has been an essential and challenging goal in the $21^{\text {st }}$ century. This exploratory research study attempted to characterize how CT is being fostered in Portuguese HEI. Semi-structured interviews were carried-out with 5 university teachers from different domains, focusing several topics: CT notion, CT aims, CT approach, interventions, teaching strategies, learning materials, assessment methods, challenges and barriers. Results highlighted the undervalue of CT dispositions by university teachers, the lack of clarity regarding the design principles and criteria behind effective $\mathrm{CT}$ instruction and assessment, and the need to change institutional culture and conditions towards the support of CT educational practices - this will also enable the long-term integration of $C T$ across the curricula and the transferability of skills and dispositions to other contexts. In general, teachers agreed on the importance to be explicit and clear in their CT teaching practice, and on the use of authentic situations, dialogue and active learning strategies for the effective development of students' CT.
\end{abstract}

Keywords—critical thinking, skills, dispositions, Higher Education Institutions, learning, assessment

\section{INTRODUCTION}

The aim of this paper is to contribute to the understanding on how Critical Thinking (CT) is being fostered in Portuguese Higher Education Institutions (HEI), taking into account the current educational interventions carried-out by different university teachers. This study was conducted in the scope of a broader project, involving 9 European countries, intended to propose guidelines for quality in CT education in HEI (project

This work was supported by the 'Critical Thinking Across the European Higher Education Curricula - CRITHINKEDU' project, with the reference number 2016-1-PT01-KA203-022808, funded by the European Commission/EACEA, through the ERASMUS+ Programme. For more information, please visit http://crithinkedu.utad.pt/en/crithinkedu/
CRITHINKEDU - Critical Thinking across the European Higher Education Curricula). In order to get a better insight of the instructional practices used to promote CT in Portuguese HEI, 5 university teachers (hereafter, "teachers") from different scientific domains and disciplines, e.g., Biomedical Sciences, STEM, Social Sciences, were interviewed. Besides the examination of CT aims, the overall approach to CT, the type of intervention, the teaching strategies, the learning materials, and the learning assessment, interviews intended also to identify the challenges and barriers found by teachers in the adoption and implementation of CT educational practices.

\section{BACKGROUND}

There are many conceptions of CT, in different domains (mainly in philosophy, psychology, and didactics) related with diverse research concerns (e.g., [1, 2]). In this study, we assume the concept of CT presented by Facione in the Delphi report [3], whose definition represents a consensus statement from a panel of experts regarding CT and the ideal critical thinker. Facione's definition points out at a set of skills involved in CT, but it also focuses the inquiry nature of CT and its potential for personal and social life:

We understand critical thinking to be purposeful, self-regulatory judgment which results in interpretation, analysis, evaluation, and inference, as well as explanation of the evidential, conceptual, methodological, criteriological, or contextual considerations upon which that judgment is based. CT is essential as a tool of inquiry. As such, CT is a liberating force in education and a powerful resource in one's personal and civic life. While not synonymous with good thinking, $\mathrm{CT}$ is a pervasive and self-rectifying human phenomenon [3, p. 2]. 
In this conception, $\mathrm{CT}$ is also assumed as a set of dispositions:

The ideal critical thinker is habitually inquisitive, well-informed, trustful of reason, open-minded, flexible, fair-minded in evaluation, honest in facing personal biases, prudent in making judgments, willing to reconsider, clear about issues, orderly in complex matters, diligent in seeking relevant information, reasonable in the selection of criteria, focused in inquiry, and persistent in seeking results which are as precise as the subject and the circumstances of inquiry permit [3, p. 2].

In the literature, it is broadly acknowledged that CT is expressed not only by cognitive elements, but also by propensity factors, like attitudes and dispositions [4, 5, 6], thus promoting the development of the individual as a person. It's also common to assume CT as intellectual attitudes and habits of mind [7], entailing a reflective basis for decision making and judgement, as well as a set of affective states and virtues - also named as "critical spirit" [8] or "spirit of inquiry" [9]. Still, a critical thinker is seen as someone who is able not only to start or engage in a thoughtful task, but also to be persistent and/or willing to do so [6]. Some authors strengthen also a sociocultural dimension of CT, in pair with personal skills and dispositions. In this sense, CT includes the ability "to participate critically in the communities and social practices of which a person is a member" [10, p. 375], [11]. Also Facione connected CT to one's role in society, as he concludes the definition of CT highlighted above saying that educating good thinkers "combines developing CT skills with nurturing those dispositions which consistently yield useful insights and which are the basis of a rational and democratic society" [3, p. 2]. Moving from the traditional sense of CT, Barnett [12] uses the term "criticality" in order to incorporate the individual's wider identity and participation/action in the world. In brief, criticality is presented by Barnett as having its scope in three domains: "formal knowledge, the self, and the world" [13, p. 63], which entail critical reason (thinking), critical self-reflection (being) and critical action (acting).

Across the different movements in CT education and research, it's nowadays consensual that $\mathrm{CT}$ is an essential skill for acquiring knowledge, for personal domain and for citizenship. Considering the labor market, CT is a major asset for graduates' employability and successful integration in society [14].

Educators have an important role in promoting CT skills, dispositions and attitudes in class. In respect to HEI, some researchers reinforce the need of wider models of CT, incorporating also concerns as:

How critical thinking is represented in debates about critical pedagogy, the role of education in leading to individual and collective sociopolitical activism, the place of critical thinking in educating for citizenship, the role of critical thinking in relation to creativity" $[2, p$. 43].

Efforts should focus on the development and daily practice of $\mathrm{CT}$, across disciplines and the curriculum, and this implies a strategic role of academic leaders in providing policy and support to promote CT education as part of the organizational culture - driving institutional change by quality standards, pedagogical models and practices.
The extent to how critical thinking can and should be taught has called researchers' attention since the early and mid-1980s $[15,16,17,18,19]$. The recognition of CT development by scholars/educators, employers and society in general has stimulated the re-design of general and domain-specific courses, the reviewing of instructional methods, and the search for the most effective interventions at improving students' CT skills and dispositions. There are many well-developed models intended to educate for critical thinking, as Davies points out [2, p. 43]: some models advanced along Bloom's taxonomy of educational objectives [20]; others developed in relation to cognitive decision-making [5]; and some widespread models followed the APA Delphi and the Paul-Elder's proposals [3, 21, 22].

Teaching CT is a challenging matter. Some researchers argue that CT can only be taught in the context of a specific domain and agree on the importance of background and/or domainspecific knowledge as a precondition to CT development [23, 24]. Some support that CT transfer across domains may only occur if students are provided with opportunities to practice these skills in a variety of domains and if they are explicitly taught to transfer [25]. Evidence suggests that academics' and employers' conceptualization of generic attributes and professional skills commonly subsumed in CT are influenced by the domain of the discipline in which they are taught and/or practiced [26, 27, 28]. In particular, this is because valid evidence, arguments, and standards tend to vary across domains, depending upon the epistemological context [29].

Assuming the teachability of CT, researchers have been proposing different instructional approaches. According to the Delphi panel experts [3], CT cannot be considered as a body of knowledge to be delivered to students as one more school subject along with others; instead, CT can occur in programs with discipline-specific content or in programs that rely on the events of everyday life as the basis for developing one's CT. The question whereas CT should be a separated course or should be embedded in standard courses divides some authors. Ennis [25] categorized the various approaches to CT instruction as general, infusion, immersion, and mixed: in the general approach, CT abilities and dispositions are taught separately from the content of the subject matter; in the infusion approach, CT is integrated in subject-matter instruction and general principles of CT are made explicit; in the immersion approach, CT is also integrated in subject matter instruction, but general CT principles and procedures are not made explicit to students; in the mixed approach, there is a combination of the general approach with either the infusion or the immersion approach, and CT is taught as an independent track within a specific subject.

Teaching strategies to promote students' CT have always been in the minds of researchers. In a comprehensive vision for a HE program incorporating CT across the curriculum, Ennis [30] recommends two basic teaching methods, both helpful, depending on the situation, the subject, the students, and the teacher: Lecture-Discussion Teaching (LDT) and ProblemBased Learning (PBL). LDT, the most common approach to college teaching in Ennis' proposal, is described as a lecture presenting one or more aspects of the subject matter, followed by a discussion; PBL is more suitable for dealing with issues that require investigating, developing, testing, and discussing of hypotheses or solutions and possible alternatives. In addition, 
Ennis suggests a selection of twenty-one strategies and tactics for teaching CT (presented in [31]). According to Niu, BeharHorenstein and Garvar [32], and to Pithers and Soden [33], PBL is one of the most widely-used learning approaches in CT instruction because it is motivating, challenging and enjoyable.

In the literature on teaching strategies, there are either proposals focused in some aspects of CT, or general guidelines intended to the overall fostering of CT in students. Supported in his own experience and many researchers, Ennis [30] endorses the general teaching guideline "We learn what we use", and he recommends two basic and complementary teaching practices: to make CT principles explicit when they are used or relevant; and to teach for transfer, that is, to promote transferring the application of CT dispositions, abilities, criteria, and principles at a variety of new examples in new contexts. Several CT researchers recommend a collaborative or cooperative approach to instruction $[3,18,34,35,36,37]$. These approaches highlight the potential for cognitive, attitudinal, and interpersonal improvements when students interact with one another, in peer activities or in working groups. To sum up, literature concerning the promotion of $\mathrm{CT}$ in education discusses interventions ranging from self-study, mentoring, dialogue, essays' or arguments' writing, peer-assessment, to experiment and authentic situations; learning strategies and methods more discussed are lecture discussions, argumentation, role-playing, inquiry, peer-review, peer-observation, self-evaluation, conceptual mapping, cooperative learning, case studies and problem solving [38].

Teachers' decision about which learning strategies to implement depends strongly in the analysis of the effectiveness of CT instruction. Despite the large number of researches about teaching CT in HEI, there is little agreement regarding the conditions under which instruction could result in greater CT outcomes [34, 39, 40, 41, 42, 43]. In their review of research on CT instruction effectiveness, Tiruneh, Verburgh and Elen [41] conclude that it is influenced by conditions in the instructional environment comprising the instructional variables (teaching strategies and CT instructional approaches), and to some extent by student-related variables (year level and prior academic performance). They found evidences of a shift towards embedding CT instruction within academic disciplines, but they concluded that there wasn't enough evidence to support effectiveness of particular instructional strategies in fostering acquisition and transfer of CT skills.

Strongly imbricated in the evaluation of learning methods to improve CT, it is still more challenging the assessment of (progresses) in acquisition of CT by students. In general, researchers argue that assessment must be addressed early and continuously, with prompt feedback to students, and it must be done having diagnostic, formative and summative purposes, at different moments of learning interventions, helping educators to learn about students' accomplishments and to plan future interventions. There are many tests to assess students' CT, including some well-established, and with regular actualizations, as the Watson-Glaser Critical Thinking Appraisal [44], the California Critical Thinking Skills Test [45], the Cornell Critical Thinking Tests (CCTT), levels X and Z [46, 47], the Halpern Critical Thinking Assessment [48], and the Collegiate Learning Assessment [49]. The literature refers mainly to these tests or their adaptations to other languages, but some new proposals are arising and being widespread (e.g., [50, 51, 52]). The numerous existing tests vary widely in the kind of measures, formats (e.g., standardized or not, open- or closed-ended questions, multiplechoice questions or writing essays or arguments), purposes, tasks demanded, time to perform the tests, students' age they are addressed to, and dimensions of $\mathrm{CT}$ on focus (some assess general skills or abilities, and others are specific to knowledge domain or some aspects of CT).

\section{Methodology AND DATA COLLECTION}

We carried-out semi-structured interviews with 5 Portuguese university teachers (Table I), all of them with relevant publications on CT education and committed to the promotion of CT in their own classes. Interviewed teachers (IT) were asked to describe their perceptions about CT teaching, namely: how can CT be promoted in HE; what type of interventions, teaching strategies, and evaluation methods that are being used to promote $\mathrm{CT}$; and what challenges and limitations teachers have to face nowadays in their CT instruction.

The interviews were carried-out individually, face-to-face or online (via Skype), and lasted about 64 minutes each. The teachers' selection for the interviews was based on their previous experience in CT education and field categorization; they came from different domains in order to obtain an integrated view on $\mathrm{CT}$ instruction at the university level.

\section{TABLE I. DISTRIBUTION OF THE INTERVIEWED TEACHERS}

\begin{tabular}{|l|c|}
\hline Domain & Interviewed teachers (IT) \\
\hline Engineering / STEM & 2 \\
\hline Social Science & 2 \\
\hline Biomedical Sciences & 1 \\
\hline TOTAL & $\mathbf{5}$ \\
\hline
\end{tabular}

The interviews guide was based on interview protocol of Paul, Elder and Bartell [53] about teacher preparation for instruction in CT. The interviews were organized in 8 openended questions: (1) How would you explain to me your concept/idea of CT?; (2) What particular aspects of CT do you believe are most important for your students to develop? And why? (3) Could you describe the practices (approaches/ strategies/interventions) that you use in your classroom to foster CT? Please, give an example; (4) Which learning materials do you use to promote CT in your classroom?; (5) Do you assess CT abilities of your students? And how?; (6) What challenges do you experience when developing CT in your students? How do you try to address them?; and (7) Are there any institutional barriers that limit the promotion of CT education?

The interviews, conducted in the mother tongue (Portuguese) were audio-recorded and transcribed. Interview contents were subjected to qualitative content analysis [54]. Content analysis matrixes were organized into dimensions and categories for the analysis. We conducted the analyses process for all teachers' responses, question-by-question, following 4 stages:

1) Decontextualization (break down the text into smaller meaning units): researchers got familiarized with the data and read through the transcript to obtain the sense of the whole, before it could be broken down into smaller meaning units. By "meaning units" we refer to the constellation of sentences or 
paragraphs containing aspects related to each other, covering different dimensions of CT addressed in the interview.

2) Recontextualization: after the meaning units were identified in the transcript, we confirmed whether all aspects of the content had been covered.

3) Coding in pre-established categories: teachers' responses were coded into the main categories and subcategories defined previously. The rubric used for the analysis of the literature reviewed served this goal, although two more dimensions were added: CT instruction in teachers' training and institutional barriers. This process of responses categorization was based through deductive reasoning and was carefully reviewed.

4) Description of the results and quotes: results were illustrated with quotes from interviews in order to provide readers with a clear idea about how university teachers promote $\mathrm{CT}$ in their classes.

The script of the semi-structured interviews and the content analysis matrixes were previously built based on systematic literature' reviews about $\mathrm{CT}$ and educational interventions, namely $[3,25,30,34,39,41]$. The conception and validity of content analysis matrixes were conducted by an iterative review process between two teams of the project (the Spanish and the Belgian partners). Following the same matrixes, international partners carried out the content analysis of the interviews that they had conducted at national level.

In the content analysis of Portuguese interviews, we applied a cyclical process of improvement, synthesis, and reflection. In a first moment, one researcher created the content analysis matrixes. After this, another researcher independently validated or suggested changes to these content analysis matrixes. They were discussed later until both researchers reached an agreement. Lastly, after translation to English when necessary, the final version of the content analysis matrixes was validated by all the research partners.

\section{RESULTS AND DISCUSSION}

The results are organized in eight subsections, each one representing the different questions asked to the participant teachers. Each subsection has a table containing the dimensions, categories of the analysis and the number of teachers who mentioned each category. This information is complemented with sample quotes from teachers.

\section{A. Question $1-C T$ notion}

All interviewed teachers $(n=5)$ define CT accordingly the Facione definition [3]. Teachers conceptualize CT as a "set of skills and/or dispositions". For example:

For me CT is to think better ... is to develop some mental processes that allow us to raise the standard, the quality level of our thinking ... I understand it more by achieving a mental process that allows me to make better decisions, that allows me to solve problems, in a way that takes into account the perspectives of all, the various arguments, after a careful analysis and a comparison/analysis of the evidence, etc. Therefore, if this also requires working on self-confidence, curiosity, etc. (...). (T2, 09/06/2017)

\section{B. Question $2-C T$ aims}

In the subsection about the $\mathrm{CT}$ aims that teachers consider more important (Table II), there are more mentions to skills (21 quotations) than to dispositions (only 4 quotations). The interviewees indicated several CT skills, but "Analysis" $(n=4)$ was the one more frequently mentioned. For example:

They [students] need to be able to consider different options and especially not to follow a checklist, not to automate the way of thinking and therefore to be able to construct, analyze a situation, build with the previous knowledge that they have in order to reach new approaches, new proposals. (T5, 16/06/2017)

"Self-Regulation" was also frequently mentioned $(n=3)$, as in this sample quote:

They [students] have to become aware that there are certain mental mechanisms, and that if we apply them we will come to a better way of thinking. So yes. It would also be important, in this case, that selfconsciousness of these processes. (T2, 09/06/2017)

Other CT skills were mentioned, but less often: "Interpretation" (n=1), "Inquisitiveness" $(\mathrm{n}=1)$, "Inference" $(n=2)$, "Evaluation" $(n=2)$, and "Explanation" $(n=2)$.

TABLE II. ANALYSIS OF INTERVIEWS: CT AIMS

\begin{tabular}{|l|l|c|}
\hline Dimensions & \multicolumn{1}{|c|}{ Categories } & IT (N=5) \\
\hline \multirow{5}{*}{ Skills } & Analysis & 4 \\
\cline { 2 - 3 } & Self-regulation & 3 \\
\cline { 2 - 3 } & Evaluation & 2 \\
\cline { 2 - 3 } & Explanation & 2 \\
\cline { 2 - 3 } & Inference & 1 \\
\cline { 2 - 3 } & Interpretation & \\
\cline { 2 - 3 } & Others (not in [3]): & 2 \\
& Argumentation and Decision making & 2 \\
& Synthesis & 1 \\
& Adaptability & 1 \\
\hline \multirow{5}{*}{ Dispositions } & 1 \\
\cline { 2 - 3 } & Group work and creative thinking & 2 \\
\cline { 2 - 3 } & Questioning & 1 \\
\cline { 2 - 3 } & Self-confidence & 0 \\
\cline { 2 - 3 } & Inquisitiveness & 0 \\
\cline { 2 - 3 } & Systematicity & 0 \\
\cline { 2 - 3 } & Analyticity & 1 \\
\cline { 2 - 3 } & Opegnitive maturity & \\
\cline { 2 - 3 } & Truth-seeking & \\
\cline { 2 - 3 } & Other (not in [3]): & \\
\hline & Motivation as a general disposition & \\
\hline
\end{tabular}

Interviewees have mentioned CT skills not included in Facione categories [3], such as: "Questioning" ( $n=1)$, "Synthesis" ( $\mathrm{n}=2)$, "Group work and creative thinking" $(\mathrm{n}=1)$, "Adaptability" (n=1) and "Argumentation and Decision making" (n=2). One example referring to "Argumentation":

Is not to say 'I am for or against' - this is not CT. CT is to argue with arguments that are valid, depending on the knowledge that we have on that moment, on that context (...) Therefore, they have to be valid and reasoned arguments. What I try to develop in students is that they are able to argue and take a position. (T4, 14/06/2017)

Regarding CT dispositions, "Self-confidence" (n=2) was mentioned in these terms: 
And here I focus a lot on what is Veterinary Medicine and the practical application of theoretical knowledge, also needing to have some degree of confidence to be able to say "this is not what I see, the explanation doesn't fit and I want a different explanation or propose other one. (T5, $16 / 06 / 2017$ )

One interviewee has also mentioned a general disposition that was not in [3], namely "Motivation" $(n=1)$ :

And it is this disposition that I also need to have to react to these situations. Because it's not a purely cognitive competency, it is also motivational in nature. (T4, 14/06/2017)

\section{Question 3 -Educational practices to foster CT}

As shown on Table III, when asked about their educational practices to promote students' CT, teachers have only referred to "Immersion" $(\mathrm{n}=1)$ and "Infusion" as the overall approach, as in this quote:

So, if the questioning has no didactic intentionality, it is an inert questioning. That is, it has no direct educational results to develop CT. Well, the CT, as you know, has to be developed intentionally. No one develops indirectly, or because I did another activity. Both the questioning and the argumentation at the service of the CT has to be done intentionally. (T3, 14/06/2017)

TABLE III. ANALYSIS OF INTERVIEWS: PRACTICES TO FOSTER CT

\begin{tabular}{|l|l|c|}
\hline \multicolumn{1}{|c|}{ Dimensions } & \multicolumn{1}{|c|}{ Categories } & IT (N=5) \\
\hline \multirow{4}{*}{$\begin{array}{l}\text { Overall approach } \\
{[25]}\end{array}$} & Infusion & 4 \\
\cline { 2 - 3 } & Immersion & 1 \\
\cline { 2 - 3 } & General & 0 \\
\cline { 2 - 3 } $\begin{array}{l}\text { Specific type of } \\
\text { interventions [34] }\end{array}$ & Mixed & 5 \\
\cline { 2 - 3 } & Authentic situations & 5 \\
\cline { 2 - 3 } & Self study & 5 \\
\cline { 2 - 3 } & Mentoring & 0 \\
\hline \multirow{5}{*}{$\begin{array}{l}\text { Teaching } \\
\text { strategies }\end{array}$} & $\begin{array}{l}\text { Lecture discussions } \\
\text { (argumentation) }\end{array}$ & 6 \\
\cline { 2 - 3 } & Problem solving (inquiry) & 2 \\
\cline { 2 - 3 } & Questioning & 2 \\
\cline { 2 - 3 } & Group work & 2 \\
\cline { 2 - 3 } & Role-playing & 1 \\
\cline { 2 - 3 } & Self and peer assessment & 1 \\
\cline { 2 - 3 } & Context-based learning & 1 \\
\cline { 2 - 3 } & Cooperative Learning & 2 \\
\cline { 2 - 3 } & Flipped classroom & 2 \\
\cline { 2 - 3 } & Online peer review & 2 \\
\hline
\end{tabular}

Regarding the type of interventions, teachers mentioned:

- "Self-study" (n=5), sample quote:

Then, in the classroom, alone, individually, they analyze a text following the FRISCO grid with one or two tasks that are not requested in the FRISCO grid (T2, 09/06/2017)

- "Dialogue" (n=5), for example:

And then, they'll have to discuss and argue with me if they're thinking that the information they will get from that kind of answer is important or not to get to the final evaluation. (T5, 16/06/2017)

- And "Authentic situations" (n=5), for example:
I have had such a simple experience, for example, asking students who will be future teachers of the first and second level, to elaborate potential questions that could be asked to the children. (T4, 14/06/2017)

It is worth noting that no teacher explicitly referred to adopt "Mentoring".

Some teaching strategies usually not highlighted in the literature were mentioned by teachers, such as: "Self and peer assessment" (n=2), "Group work" $(n=2)$, "Context-based learning" $(\mathrm{n}=1)$, "Questioning" $(\mathrm{n}=3)$, "Online peer review" $(\mathrm{n}=1)$, "Cooperative Learning" $(\mathrm{n}=1)$, and "Flipped classroom" $(\mathrm{n}=1)$

\section{Question 4-Learning materials}

TABLE IV. ANALYSIS OF INTERVIEWS: LEARNING MATERIALS

\begin{tabular}{|c|c|c|}
\hline Dimensions & Categories & $\underset{(\mathrm{N}=5)}{\mathrm{IT}}$ \\
\hline \multirow{18}{*}{$\begin{array}{l}\text { Learning } \\
\text { materials } \\
\text { (including } \\
\text { features of } \\
\text { tasks) }\end{array}$} & $\begin{array}{l}\text { Tasks intended for university students to } \\
\text { develop CT and learning materials used } \\
\text { for this goal (e. g., video, lecture notes): }\end{array}$ & (5) \\
\hline & $\begin{array}{l}\text { Problem situations/cases of a business } \\
\text { company; }\end{array}$ & 5 \\
\hline & Articles/papers/videos/presentations & 3 \\
\hline & Questions & 3 \\
\hline & Role-play & 3 \\
\hline & Conceptual maps & 2 \\
\hline & $\begin{array}{l}\text { Group discussion using a problem } \\
\text { situation/case to solve or take a decision }\end{array}$ & 2 \\
\hline & $\begin{array}{l}\text { Self and peer-assessment using a rubric } \\
\text { in an online tool }\end{array}$ & 2 \\
\hline & $\begin{array}{l}\text { Written reports and oral presentation } \\
\text { recordings }\end{array}$ & 2 \\
\hline & Diagnosis algorithms & 1 \\
\hline & Hypothetical situations/cases; & 1 \\
\hline & $\begin{array}{l}\text { Online peer review with the analysis of } \\
\text { a written document, using an } \\
\text { appropriate template, the FRISCO grid } \\
\text { and the SWOT framework }\end{array}$ & 1 \\
\hline & Paper sheets; & 1 \\
\hline & Socrative mobile app & 1 \\
\hline & $\begin{array}{l}\text { Tasks intended for university students to } \\
\text { transfer CT to their target and learning } \\
\text { material used for this goal (e.g., video, } \\
\text { lecture notes): }\end{array}$ & (2) \\
\hline & $\begin{array}{l}\text { Questions; small cards with generic } \\
\text { questions }\end{array}$ & 2 \\
\hline & ArguQuest digital tool & 1 \\
\hline & Problem situations/cases & 1 \\
\hline
\end{tabular}

All interviewed teachers have mentioned several tasks and learning materials intended for HEI students to develop CT $(n=5)$ (Table IV). All interviews focused the "Problem situations or cases" $(n=5)$, for example:

\footnotetext{
We created scenarios (problem situations) in which they have to solve them to be able to develop those skills that are in deficit (...) situations are created and have to be related with the topics of the curricular unit (...) Basically they are pedagogical scenarios, case studies, situations that are being created and adapted. I also look for news from other contexts. The videos are also something that interests me a lot. And then I also ask them to bring things that they can discuss. (T4, 14/06/2017)
}

In contrast, few teachers $(n=2)$ mentioned specific tasks and learning materials for HEI students to transfer CT. 


\section{E. Question 5 - Assessment methods}

In this subsection, we can see in table $\mathrm{V}$ that teachers both adopt formative and summative assessment. Almost all interviewees $(n=4)$ said they use the formative assessment with feedback $(n=4)$, sample quote:

We strive to give feedback during the process, to be formative rather than summative (...) I analyze the questions almost as if they were answers or interviews from the students, and I can extract meanings from the questions that often are not possible in a practical and viable way. (...) I can through a taxonomic system categorize these questions in a quick and simple way (...) That is, I can follow, through the pattern of questioning, the quality of the questions, the role of the questions, their nature, the elements that allow me to evaluate these questions and, therefore, indirectly the CT. (T3, 14/06/2017)

Interviewees mentioned assessment instruments in general, for the formative and summative evaluation of activities that they carry out in their classes.

TABLE V. ANALYSIS OF INTERVIEWS: ASSESSMENT METHODS

\begin{tabular}{|l|l|c|}
\hline Dimensions & \multicolumn{1}{|c|}{ Categories } & IT (N=5) \\
\hline \multirow{5}{*}{ Assessment } & Formative assessment with feedback & 4 \\
\cline { 2 - 3 } & $\begin{array}{l}\text { Summative assessment } \\
\text { Grading of the final written assignment }\end{array}$ & 1 \\
\cline { 2 - 3 } & $\begin{array}{l}\text { Formative assessment } \\
\text { Teacher' feedback during and after each } \\
\text { activity; Self and Peer-assessment after each } \\
\text { activity }\end{array}$ & $\begin{array}{l}\text { Formative assessment with pre and post-test } \\
\text { Thinking Test (CCTT) }\end{array}$ \\
\cline { 2 - 3 } & $\begin{array}{l}\text { Summative assessment with grading and } \\
\text { feedback of the written peer reviewed } \\
\text { documents }\end{array}$ & 1 \\
\cline { 2 - 3 } & $\begin{array}{l}\text { Summative assessment with grading of the } \\
\text { type of students' questions resulting from the } \\
\text { group work discussions }\end{array}$ & 1 \\
\hline
\end{tabular}

\section{F. Question 6-CT Challenges}

There are several CT challenges mentioned by teachers (Table VI), which may be distributed in four categories (classroom settings and organization, teachers and student's mindset, CT skills assessment, and other categories).

The main challenges teachers pointed out was "Teachers' and students' mindset" $(\mathrm{n}=5)$, for example:

The main challenge to develop CT is this inertia. Critical thinking requires energy, and this energy is not much sought in our educational system and process. (...) So one of the main challenges is that the development of CT gives teachers work, but also gives students work, and this, to take students from inertia, to pull them to question, to argue, etc. (...) The very barrier is the teacher, because a teacher who is not trained or sensitized to CT, he/she will hardly develop it (...) (T3, $14 / 06 / 2017$ )

And also the "Time, Size and duration of classes", as in this example:

And then the number of contact hours that is relatively small for such activities in a theoretical class - I should have enough hours that allow me to meet the schedule or course syllabus. (T5, 16/06/2017)
TABLE VI. ANALYSIS OF INTERVIEWS: CT CHALLENGES

\begin{tabular}{|l|l|c|}
\hline Dimensions & \multicolumn{1}{|c|}{ Categories } & IT (N=5) \\
\hline \multirow{5}{*}{ Challenges } & Teachers' and students' mindset & 5 \\
\cline { 2 - 3 } & Time, Size and duration of classes & 4 \\
\cline { 2 - 3 } & $\begin{array}{l}\text { CT assessment (both summative and } \\
\text { formative) }\end{array}$ & 1 \\
\cline { 2 - 3 } & CT in a digital world & 1 \\
\cline { 2 - 3 } & $\begin{array}{l}\text { CT skills assessment (inadequacy of the } \\
\text { current formal tests, such as the CCTT) }\end{array}$ & 1 \\
\cline { 2 - 3 } & CT skills assessment (transfer) & 1 \\
\cline { 2 - 3 } & Difficulty to implement some activities & 1 \\
\cline { 2 - 3 } & Students' engagement with CT & 1 \\
\cline { 2 - 3 } & Support & 1 \\
\cline { 2 - 3 } & Teachers' commitment & 1 \\
\cline { 2 - 3 } & Teachers' resistance in being observed & 1 \\
\cline { 2 - 3 } & Technical bugs & 1 \\
\hline
\end{tabular}

\section{G. Question 7 - Institutional barriers}

Interviewees have pointed three institutional barriers (Table VII). All teachers mentioned as an institutional barrier the lack of recognition of "CT as institutional priority" $(n=5)$, example:

\begin{abstract}
and then, effectively, have institutional support. That the whole institution, especially the top management and leaders, recognize this work (because I think teachers also like to be recognized), that they recognize that it's valid and it will take the university to another level of quality teaching. And that, if they feel it, and a kind of requirement ... I see in the evaluations, in the RADE (the institutional regulation for teachers' performance evaluation), which says: "integrates innovative methods.". But, what are innovative methods? How they evaluate them? Who evaluates? (...) by the evaluation system of teachers, this does not seem to be valued, because it's only one more insignificant element.. (T2, 09/06/2017)
\end{abstract}

The interviewees mentioned the institutional culture as a barrier to promote the development of CT skills in university and among teachers and students $(n=3)$, sample quote:

Because what I have seen, with almost 38 years of service and teaching, is that these skills have been lost. Because I also think that the university shapes the students' thinking more than deforms it. It deforms in the sense that people have divergent thinking, but they don't. People are trained to have convergent thinking, to think all in the same way. Does this also apply to teachers? Yes. Because we also value those who think like us. (T4, 14/06/2017)

Still, one teacher exposed the lack of University-Business cooperation in the curricula.

TABLE VII. ANALYSIS OF INTERVIEWS: INSTITUTIONAL BARRIERS

\begin{tabular}{|l|l|c|}
\hline \multicolumn{1}{|c|}{ Dimensions } & \multicolumn{1}{|c|}{ Categories } & IT (N=5) \\
\hline \multirow{2}{*}{$\begin{array}{l}\text { Institutional } \\
\text { barriers for } \\
\text { promoting }\end{array}$} & CT as institutional priority & 5 \\
\cline { 2 - 3 } CT & Institutional culture & 3 \\
\cline { 2 - 3 } & $\begin{array}{l}\text { Lack of University-Business cooperation } \\
\text { in the curricula }\end{array}$ & 1 \\
\hline
\end{tabular}

\section{CONCLUSIONS}

All teachers interviewed adopted the definition/concept of CT presented in the Delphi report [3], but they referred mainly to skills, and scarcely mentioned dispositions. In future work it will be important to understand why the CT dispositions are less referred. 
The interviewees pointed out immersion and infusion as the most used approaches to integrate CT in their daily classroom practices. It is important in future work to ascertain and understand whether for teachers in Higher Education the concept of CT is clear in their professional practice and how this is reflected in the instructional design of their courses. Also, it is important to understand how the institutional context influences the adoption of teachers' pedagogical approaches to promote $\mathrm{CT}$ and if teachers have the necessary training to integrate them in their practice. As Abrami and colleagues stated [34], a crucial factor for adoption of strategies that promote CT skills and dispositions is related to experience, training and background on CT. In this way, for practical implications of this work, teachers' training is recommended as well as all the support needed to enhance the pedagogical practices promoting students' CT.

Except the Mentoring, all other types of interventions are adopted by the interviewed teachers. Here, the use of Authentic Situations (e.g., real-world scenarios and case studies) and Dialogue seem to be effective ways to foster CT development in higher education students. Considering the various types of teaching strategies, the most common among the teachers interviewed is problem-solving. Regarding the learning materials that teachers use for the development of critical thinking, and although their wide variety, only two teachers referred to use materials and/or resources which promote the transfer of critical thinking in different contexts. In future work, it is recommended to deeper the analysis on this transferability issue.

Regarding CT assessment, all teachers adopt formative and summative evaluation strategies and/or tools, and there is a greater incidence in the formative evaluation type with continuous feedback. However, there is a lack of explanation and clarity on how teachers apply and practice it. In future work, it is recommended to verify if teachers have enough knowledge about how to assess CT development of their students, as well as to better understand in what extent these formative strategies can be integrated within the teaching practice. Also, and attending that the educational interventions reported in this study are short-term, will be important to analyze how CT can be fostered across the curricula, in a more systematic way, attending to the longitudinal and mid-term setting that better enable the development of CT dispositions.

The teachers interviewed emphasize, as for the challenges in CT education, the need to change the students and teachers' mindset (change of the institutional culture). Also, other challenges and difficulties are mentioned, namely: the lack of institutional support in the promotion of CT; difficulty in implementing activities due to the size of the class (high number of students), organizational conditions (class length), which are in line with [55].

\section{LIMITATIONS}

The overall results obtained in interviews with Portuguese teachers at HEI are in general coherent with findings in the literature. Nevertheless, there are some limitations that demand future work: the sample size (few number of interviewees), and representativeness (limitation of the scientific domains). Notwithstanding, this study characterize some of the current CT educational practices that has been adopted in different Portuguese universities. Notwithstanding, this study characterize some of the current CT educational practices that has been adopted in different Portuguese universities. Future studies should include more university teachers from different domains and the comparison of their perceptions with the empirical studies already reported in the literature regarding the CT educational interventions within the Portuguese HEI landscape [56].

\section{ACKNOWLEDGMENT}

This work was supported by the 'Critical Thinking Across the European Higher Education Curricula - CRITHINKEDU' project, with the reference number 2016-1-PT01-KA203022808, funded by the European Commission/EACEA, through the ERASMUS+ Programme.

\section{REFERENCES}

[1] R. Paul, "Critical thinking movement: 3 waves," 2011. [Online]. Available: http://www.criticalthinking.org/pages/critical-thinkingmovement-3-waves/856.

[2] M. Davies, "A Model of Critical Thinking in Higher Education," in Higher Education: Handbook of Theory and Research, vol. 30, M. B. Paulsen, Ed. Springer, 2015, pp. 41-92.

[3] P. A. Facione, Critical Thinking: A Statement of Expert Consensus for Purposes of Educational Assessment and Instruction. Mellbrae, CA: The California Academic Press, 1990.

[4] J. Halonen, "Demystifying Critical Thinking," Teach. Psychol., vol. 22, no. 1 , pp. 75-81, 1995.

[5] R. H. Ennis, "Critical Thinking: A Streamlined Conception," Teach. Philos., vol. 14, no. 1, pp. 5-24, 1991.

[6] D. F. Halpern, Thought \& Knowledge: An Introduction to Critical Thinking, 4th ed. New Jersey: Lawrence Erlbaum Associates, 2003.

[7] P. A. Facione, C. A. Giancarlo, N. C. Facione, and J. Gainen, "The disposition toward critical thinking," J. Gen. Educ., vol. 44, no. 1, pp. 1$25,1995$.

[8] H. Siegel, Educating Reason: Rationality, Critical Thinking, and Education. New York: Routledge, 1988.

[9] S. Bailin and M. Battersby, Reason in the Balance: An Inquiry Approach to Critical Thinking. Whitby, ON: McGraw-Hill Ryerson, 2010.

[10] G. ten Dam and M. Volman, "Critical thinking as a citizenship competence: teaching strategies," Learn. Instr., vol. 14, no. 4, pp. 359379, Aug. 2004.

[11] M. Volman and G. ten Dam, "Critical Thinking for Educated Citizenship," in The Palgrave Handbook of Critical Thinking in Higher Education, M. Davies and R. Barnett, Eds. New York: Palgrave Macmillan, 2015, pp. 593-603.

[12] R. Barnett, Higher Education: A Critical Business. Buckingham: Society for Research into Higher Education and the Open University Press, 1997.

[13] R. Barnett, "A Curriculum for Critical Being," in The Palgrave Handbook of Critical Thinking in Higher Education, M. Davies and R. Barnett, Eds. New York: Palgrave Macmillan, 2015, pp. 63-76.

[14] C. Dominguez, Coord., A European collection of the Critical Thinking skills and dispositions needed in different professional fields for the 21 st century. Vila Real: UTAD, 2018, ISBN: 978-989-704-256-0.

[15] H. Siegel, "Critical Thinking as an Educational Ideal," Educ. Forum, vol. 45, no. 1, pp. 7-23, 1980.

[16] J. E. Stice, Developing Critical Thinking and Problem-Solving Abilities, 
vol. 30. San Francisco: Jossey-Bass, 1987.

[17] R. E. Young, Fostering Critical Thinking, vol. 3. San Francisco: JosseyBass, 1980.

[18] D. F. Halpern, "Teaching for Critical Thinking: Helping College Students Develop the Skills and Dispositions of a Critical Thinker," New Dir. Teach. Learn., no. 80, pp. 69-75, 1999.

[19] D. F. Halpern, Critical Thinking Across the Curriculum. A Brief Edition of Thought and Knowledge. New York: Lawrence Erlbaum Associates, 1997.

[20] P. W. Airasian, K. A. Cruikshank, R. Mayer, P. R. Pintrich, J. Raths, and M. C. Wittrock, A Taxonomy for Learning, Teaching, and Assessing: A Revision of Bloom's Taxonomy of Educational Objectives. New York: Longman, 2001.

[21] R. Paul and L. Elder, A Guide for Educators to Critical Thinking Competency Standards. Foundation for Critical Thinking Press, 2007

[22] R. Paul and L. Elder, Critical thinking: Tools for taking charge of your learning and your life. Boston: Pearson, 2012.

[23] J. E. McPeck, Teaching critical thinking: Dialogue and dialectic. New York: Routledge, 1990.

[24] D. T. Willingham, "Critical thinking: why is so hard to teach?," Arts Educ. Policy Rev., vol. 109, pp. 21-32, 2008.

[25] R. H. Ennis, "Critical Thinking and Subject Specificity: Clarification and Needed Research," Educ. Res., vol. 18, no. 3, pp. 4-10, 1989.

[26] A. Jones, "Re-disciplining Generic Attributes: The Disciplinary Context in Focus," Stud. High. Educ., vol. 34, no. 1, pp. 85-100, 2009.

[27] S. Grace and P. J. Orrock, "Criticality in Osteopathic Medicine: Exploring the Relationship between Critical Thinking and Clinical Reasoning," in The Palgrave Handbook of Critical Thinking in Higher Education, M. Davies and R. Barnett, Eds. New York: Palgrave Macmillan, 2015, pp. 475-490.

[28] S. Sin, A. Jones, and Z. Wang, "Critical Thinking in Professional Accounting Practice: Conceptions of Employers and Practitioners," in The Palgrave Handbook of Critical Thinking in Higher Education, New York: Palgrave Macmillan, 2015, pp. 431-456.

[29] A. Jones, "Generic Attributes in Accounting: The Significance of the Disciplinary Context," Account. Educ. An Int. J., vol. 19, no. 1-2, pp. 5$21,2010$.

[30] R. H. Ennis, "Critical Thinking Across the Curriculum: A Vision," Topoi, vol. 37, no. 1, pp. 165-184, 2018.

[31] R. H. Ennis, "Reflection and perspective," Inq. Crit. Think. across Discip. vol. 26, no. 1, pp. 4-18, 2011.

[32] L. Niu, L. S. Behar-Horenstein, and C. W. Garvan, "Do instructional interventions influence college students' critical thinking skills? A metaanalysis," Educ. Res. Rev., vol. 9, pp. 114-128, Jun. 2013.

[33] R. T. Pithers and R. Soden, "Critical thinking in education: A review," Educ. Res., vol. 42, no. 3, pp. 237-249, 2000

[34] P. C. Abrami, R. M. Bernard, E. Borokhovski, D. I. Waddington, A. C. Wade, and T. Persson, "Strategies for Teaching Students to Think Critically: A Meta-Analysis," Rev. Educ. Res., vol. 85, no. 2, pp. 275-314, 2015.

[35] H. Silva et al., "Learn to cooperate and cooperate to learn: Empowering critical thinking skills through cooperative peer review," in Pensamento Crítico na Educação: Desafios Atuais, C. Dominguez, E. Morais, F. Morais, G. Cruz, J. P. Lopes, M. H. Silva, M. J. Monteiro, M. M. Nascimento, P. Catarino, R. Payan-Carreira, and R. M. Vieira, Eds. Vila Real: UTAD, 2015, pp. 175-185.

[36] H. Silva et al., "Fostering critical thinking through peer review between cooperative learning groups," Rev. Lusófona Educ., vol. 32, pp. 31-45, 2016

[37] C. Dominguez et al., "Adding value to the learning process by on-line peer review activities: a methodology in progress," Eur. J. Eng. Educ., vol. 40, no. 5, pp. 573-591, 2015.

[38] C. Dominguez, Coord. A European review on Critical Thinking educational practices in Higher Education Institutions. Vila Real: UTAD, 2018, ISBN: 978-989-704-258-4

[39] P. C. Abrami et al., "Instructional Interventions Affecting Critical Thinking Skills and Dispositions: A Stage 1 Meta-Analysis," Rev. Educ. Res., vol. 78, no. 4, pp. 1102-1134, 2008.

[40] D. Hitchock, "The Effectiveness of Instruction in Critical Thinking," in The Palgrave Handbook of Critical Thinking in Higher Education, M. Davies and R. Barnett, Eds. New York: Palgrave Macmillan, 2015, pp. 283-294.

[41] D. T. Tiruneh, A. Verburgh, and J. Elen, "Effectiveness of Critical Thinking Instruction in Higher Education: A Systematic Review of Intervention Studies," High. Educ. Stud., vol. 4, no. 1, 2014.

[42] D. F. Halpern, "Assessing the Effectiveness of Critical Thinking Instruction,” J. Gen. Educ., vol. 50, no. 4, pp. 270-286, 2001.

[43] L. S. Behar-Horenstein and L. Niu, "Teaching critical thinking skills in higher education: A review of the literature," J. Coll. Teach. Learn., vol. 8, no. 2, pp. 25-42, 2011.

[44] G. Watson and E. M. Glaser, Watson-Glaser Critical Thinking Appraisal Manual. San Antonio, TX: Psychological Corporation, 1980.

[45] P. A. Facione, The California Critical Thinking Skills Test - College Level. Experimental Validation and Content Validity. The California Academic Press, 1990.

[46] R. H. Ennis and J. Millman, Cornell Critical Thinking Ttest, Level X. Pacific Grove, CA: Midwest Publications, 1985.

[47] R. H. Ennis and J. Millman, Cornell Critical Thinking Test, Level Z. Pacific Grove, CA: Midwest Publications, 1985.

[48] D. F. Halpern, Critical Thinking Assessment: Manual, Version 22. Mödling: Schufried, 2012.

[49] Collegiate Learning Assessment. [Online]. Available: http://cae.org/flagship-assessments-cla-cwra/cla/about-cla.

[50] S. F. Rivas and C. Saiz, "Validación y propiedades psicométricas de la prueba de pensamiento crítico PENCRISAL," Rev. Electrónica Metodol. Apl., vol. 17, no. 1, pp. 18-34, 2012.

[51] M. P. Amorim and I. Silva, "Instrumento de avaliação do pensamento crítico em estudantes e profissionais de saúde," vol. 15, no. 1, pp. 122 137, 2014.

[52] J. Lopes, H. Silva, and E. Morais, "Teste de Pensamento Crítico," unpublished, 2018.

[53] R. Paul, L. Elder, and T. Bartell, California Teacher Preparation for Instruction in Critical Thinking: Research Findings and Policy Recommendations. California Commission on Teacher Credentialing, 1997.

[54] P. Mayring, "Design," in Handbuch qualitative Forschung in der Psychologie, G. Mey and K. Mruck, Eds. Wiesbaden: Verlag, 2010, pp. 225-237.

[55] C. Saiz and S. F. Rivas, "Desarollo del Pensamiento Crítico," L. S. Almeida, Ed. Braga: Centro de Estudos e Recursos em Psicologia, 2017, pp. 133-179.

[56] G. Cruz, R. Payan-Carreira and C. Dominguez, "Critical thinking education in the portuguese higher education institutions: a systematic review of educational practices," Rev. Lusófona Educ., vol. 28, pp. 43-61, 2017. 